\title{
Monte Carlo simulated stress test scenario on the case of Macedonian logistic companies
}

\section{Riste Temjanovski, ${ }^{1}$ Dusko Todeski, ${ }^{2}$ Monika Arsova ${ }^{3}$, Janka Dimitrova}

\author{
1 University Goce Delcev Stip, Faculty of Economics, riste.temjanovski@ugd.edu.mk \\ ${ }^{2}$ University Goce Delcev Stip, Faculty of Economics, dusko.3082@student.ugd.edu.mk \\ ${ }^{3}$ University Goce Delcev Stip, Faculty of Economics, monika.arsova@ugd.edu.mk \\ ${ }^{4}$ University Goce Delcev Stip, Faculty of Economics, janka.dimitrova@ugd.edu.mk
}

\begin{abstract}
In the face of intense business competition in the global market, transport and logistics companies often do not sufficiently analyze the detailed accounting statements for the incurred costs of individual processes, nor do they pay attention to certain scenarios for more successful management of certain unnecessary costs. Numerous scientific analyzes made by the academic and business sector indicate that companies would realize significant financial benefits, if they had full insight into the financial statements structured through multiple scenario simulations, which will see possible gains and losses over a period of analysis.

The subject of this paper is to analyze the potential of logistic companies and their performance capacity though the Monte Carlo simulation of the net income values. We present the case of Macedonian logistic companies with the challenge of using the interactive testing environment in Power $\mathrm{Bi}$ for goal testing. For the purpose of testing, we generate 1 million data units in two scenarios of $10 \%$ increased and decreased net income value. This case was tested on data from year 2020 for Fershped, Kuehne \& Nagel and Quehenberger Logistics as a part of Macedonian logistic industry.

The results suggest that results of the simulations are in small favor of the values less than in the 2020. However, if we know that the values in 2020 are continuing a good result from 2019 we can conclude that the results expected for 2021 will results in strong positive values.
\end{abstract}

Kew words: Macedonian logistic companies, Net income, Monte Carlo scenario, Power BI

\section{Introduction}

The global market, which is more dynamic and frequent than ever in terms of historicaleconomic exchange of goods, dictates the requirements for various logistics services. In order to achieve a higher degree of competitiveness, companies are required to have efficiency, 
quality and competitive prices. The need for the finalization of the production from the traditional factory plants and their approach to certain logistics centers or shopping centers is increasingly imposed. Logistics operators already in the domain of their business activities have developed product packaging scenarios, planned distribution channels and a complete strategy for delivery to markets or end consumers, following the business logic for the right time and place.

Due to the trend of nationalization and globalization in recent decades, the importance of logistics management is increasing in different areas. As early as the 1980s, global competition forced companies to provide lower costs, higher quality, standardization, and greater flexibility in product delivery. In this context, several programs, techniques and technologies directly or indirectly related to logistics, such as JIT (just in time), ECR (efficient customer relationship), EDI (electronic data interchange), enabled inventory reduction and better coordination of material flow along productive supply chains.

For industries, logistics helps to optimize existing production and distribution processes based on the same resources through management techniques to enhance the efficiency and competitiveness of enterprises. A key element in the logistics chain is the transport system, which combines segregated activities. Transport accounts for one third of the cost of logistics and transport systems have a huge impact on logistics system performance. Transportation is required throughout the production process, from production to delivery to end users and back. Only good coordination between each of these components will provide adequate benefits to the maximum. [1]

According to Christopher M. [2] logistics is essentially oriented towards planning and a framework that aims to create a single plan for the flow of products and information through business. Supply chain management is based on this framework and seeks to achieve connectivity and coordination between the processes of other entities in the network, i.e. suppliers and customers, and the organization itself. Thus, for example, one goal of supply chain management may be to reduce or eliminate the inventory buffer that exists between organizations in a single chain by sharing information about demand and current levels of inventory.

According to prof. Kilibarda [3] in practice, logistics costs are often ignored because they are difficult to locate in the origin, characteristics of carriers, resources, processes, activities and products. Without this, it is impossible to streamline, manage costs and achieve savings. Existing accounting systems and spreadsheets do not allow for a more precise differentiation of costs, so analysts have trouble determining exactly where individual costs appear and belong. A special problem is the distribution and projection of general and ordinary costs. To successfully solve these problems, it is necessary to apply a special methodology and procedure for measuring and monitoring costs, i.e. preparing and distributing reports on the structure and costs. It is necessary to establish a system of logistical control, to support the decisions in each company. Two sets of problems need to be addressed. First, logistics costs need to be identified, measured and monitored, because something that has not been identified and measured cannot be rationalized and improved. Second, it is necessary to identify the causes, places of origin and drivers of costs and to define solutions and measures to reduce costs.

It is obvious that the management of transport issues, logistics and supply chain in general implies a complex and thorough professional approach. The focus of managing these components necessarily requires a strong degree of cooperation and trust between companies, so that through proper management we will reach the principle that "the whole can be greater than the sum of its parts." 


\section{Data and methodology}

Data for this paper is provided from the Central Registry of the Republic of North Macedonia with the played access to the listing of processes annual account. We use selected companies' annual reports and their financial data, primary total income, total expenses and net income

We include this companies as one of the leaders' and one of the most successful logistic companies in Macedonian economy in the recent years. The three companies included in this observation and analysis are Fershped, Kuehne \& Nagel and Quenberger. One of the criteria for the selection of the companies for this research are the sales volume and the need to compare the results from domestically owned Fershped company and foreign owned companies Kuehne \& Nagel and Quehenberger Logistics.

The idea of this paper is to create Monte Carlo simulation [4], for the selected logistic companies' data with the purpose to test two scenarios of the achievement of the goalprobability for the same or higher level of net income as achieved in financial report in 2020. Three scenarios are using data generated for net income from the starting referent value registered in year 2020, with normal distribution and with standard deviation using the difference between net income in 2020 and 2019. In the first scenario simulation of the values are under assumption that the values of net income in 2021 will be similar to those in 2020, therefore for the simulation we are using the difference between net income in 2020 and 2019 as standard deviation for data distribution. Other two scenarios are generation data increased or decrease by $10 \%$ on the values on net income and standard deviation, under the assumption that the values can vary up to $10 \%$ increase or decrease of the net income. Data is generated with NumPy, python programing language library with random function for normal distribution with the size of 1 million units.

The research goal for the scenarios we are testing for these three companies are:

1. Finding the probability percent of the net income of the three companies higher than year 2020

2. Finding the probability percent of lower net income of the three companies than year 2020

These two goals are assessed within the sample of 1 million values of net income variable data generated by normal distribution using the 2020 year as referent value for data generation.

For the purpose of evaluating the goals there are few steps which need to be performed to provide easier testing of the research goal. For the purpose of data transformation and in order to get closer to evaluating the research goals we are providing the setup testing environment with required DAX measures and visualizations in Power $\mathrm{BI}$ [5].

Some of the most important steps during the data transformation is transformation of the net income variable in 200 bins in order to have proper normal distribution visualization for the generated net income data. Next steps related to the analysis are creation of the proxy DAX measures for visualization in the form of:

$>$ Number of trials (number of simulated values)

$>\%$ Of trials

$>$ All trials

$>$ Average result of trials.

All this required DAX measures are required for the creation of the slicer which can use the option for input of the values from and to certain value. All these steps are necessary in order to test the thesis inputting value of the referent net income value for year 2020 per company. The methodology and tool created for the purpose of the research goal testing is interactive and along with the code created for data generation can create full cycle of automatization of the process of testing the research goals within this thesis. 


\section{Results and discussion}

We provided the results for the analysis from testing on reports created in Power BI for this purpose, on the sample data of one million values on net income variable generated on the 10 percent increase and decrease on referent value. In all cases via slicer in Power Bi part, we use the input referent value from the net income from year 2020 in order to calculate the probability and the average values on the simulated sample.

\subsection{Fershped}

Fersped is company for international and local freight forwarding with public and bonded warehouses. Major companies in the country as well as the Balkan region and both Western and Eastern Europe have been using the company's services in the area of transportation, customs clearance and warehousing. Our company had witnessed over the years the establishment of some of the major industrial facilities and complexes in Macedonia. (such as e.g. FENI, TEC Negotino etc.).[6]

Below are the test results for the Fershped case when we use the data values which we produced from the same level as referent value of net income of year 2020 with higher than 76,62 million denars.

Table 1 Results on data generated from generated data from referent value of net income for Ferhsped at level, $10 \%$ increased and $10 \%$ decreased simulated values with input value of $<76,62$ million denars

\begin{tabular}{|c|c|c|c|}
\hline & $\begin{array}{l}\text { \# Of } \\
\text { Trials }\end{array}$ & Probability & $\begin{array}{l}\text { Average result of net } \\
\text { income }\end{array}$ \\
\hline $\begin{array}{l}\text { Fershped } 10 \% \\
\text { increase }\end{array}$ & $652 K$ & $65,25 \%$ & $95,43 \mathrm{M}$ \\
\hline $\begin{array}{l}\text { Fershped } 10 \% \\
\text { decrease }\end{array}$ & $317 \mathrm{~K}$ & $31,71 \%$ & $87,04 \mathrm{M}$ \\
\hline
\end{tabular}

Source: Authors' calculations based on data from the Central Registry of the Republic of the North Macedonia www.crm.com.mk

Table 1 in the first case shows that in the case of values simulated with $10 \%$ increase of net income we have probability of $65,25 \%$, which is the probability for the outcome for the value of net income will be higher than referent value of net income in 2020. Calculations on tis filtered sample present average net income value od 95,43 million denars. This result indicates that we have $65,25 \%$ probability of achieving average result of 95,43 million denars, at the same time we have $34,75 \%$ probability to have same or lower result of net income in 2020 .

Second row shows that in the case of values simulated with $10 \%$ decrease of net income we have probability of $31,71 \%$ which is the probability for the outcome for the value of net income will be higher than referent value of net income in 2020. Calculations on tis filtered sample present average net income value of 87,04 million denars. This result indicates that we have $31,71 \%$ probability of achieving average result of 87,04 million denars, at the same time we have $68,29 \%$ probability to have same or lower result of net income in 2020 .

In both cases we have indications that in case of lower positive or negative trend on the result produced from the increased or decreased value of net income we can see that we can expect $65,25 \%$, and $31,17 \%$ of same or higher value than in year 2020 . Interesting fact is that lower 
probability of $31,71 \%$ is in favor for decreased probability for good result in case of undesired variations.

This shows that the half of generated values are same or higher level than in 2020. This simulation having in mind preliminary assumptions from the research goals and thesis indicates that in this scenario we can expect at least repeating the strong results of the net income from 2020.

Below are the figures representing the Power $\mathrm{BI}$ reports used as analytical tool and the test results for the Fershped case when we use the data values which we produced from the same level as referent value of net income of year 2020 with higher than 76,62 million denars (76.616.608 denars).
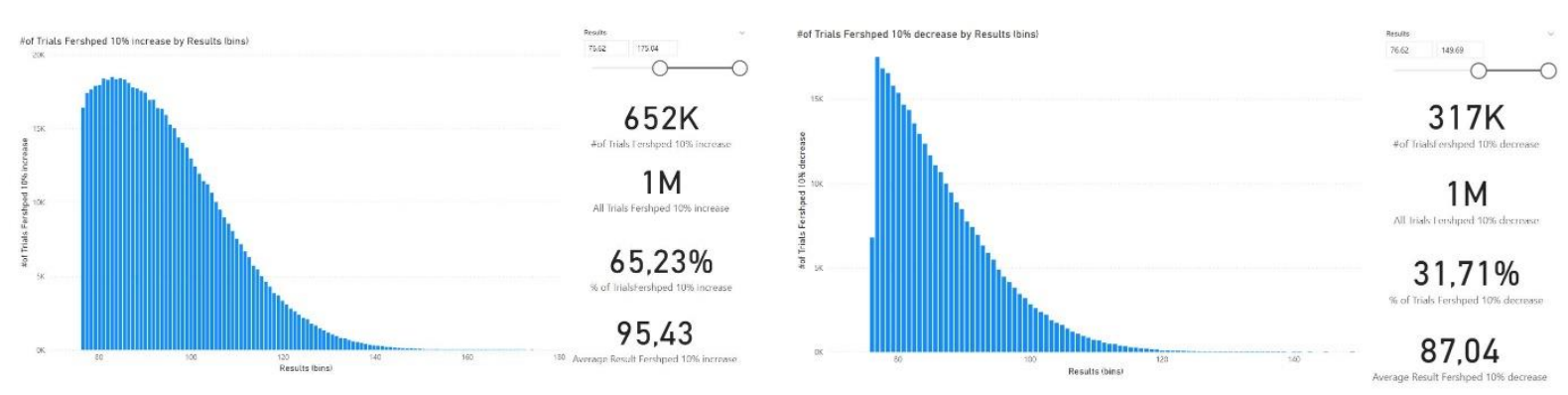

Figure 1 Power $\mathrm{BI}$ report used as analytical tool and the test results for the Fershped

Source: Authors' calculations based on data from the Central Registry of the Republic of the North Macedonia www.crm.com.mk

\subsection{Kuehne \& Nagel}

Kuehne \& Nagel is global logistics company with headquarter in Switzerland, with a presence all over the world (nearly 1400 locations worldwide). Over 130 years, Kuehne \& Nagel has envolved from a traditional shipping company to a global logistics partner that offers highly specialized solutions for major industries worldwide.[7]

Below are the test results for the Kuehne \& Nagel case when we use the data values which we produced from the same level as referent value of net income of year 2020 with higher than 16.083212 million denars.

Table 1 Results on data generated from generated data from referent value of net income for Kuehne \& Nagel at level, $10 \%$ increased and $10 \%$ decreased simulated values with input value of $<16.083212$ million denars

\begin{tabular}{|c|c|c|c|}
\hline & \# Of Trials & Probability & $\begin{array}{l}\text { Average result of net } \\
\text { income }\end{array}$ \\
\hline $\begin{array}{l}\text { Kuehne \& Nagel 10\% } \\
\text { increase }\end{array}$ & $698 \mathrm{~K}$ & $69,82 \%$ & $19,24 \mathrm{M}$ \\
\hline $\begin{array}{l}\text { Kuehne \& Nagel 10\% } \\
\text { decrease }\end{array}$ & $262 K$ & $26,21 \%$ & $17,62 \mathrm{M}$ \\
\hline
\end{tabular}

Source: Author's own calculations based on data from the Central Registry of the Republic of the North Macedonia www.crm.com.mk

Table 2 in the first case shows that in the case of values simulated with $10 \%$ increase of net income we have probability of $69,82 \%$, which is the probability for the outcome for the value of 
net income will be higher than referent value of net income in 2020. Calculations on tis filtered sample present average net income value of 19,24 million denars. This result indicates that we have $69,82 \%$ probability of achieving average result of 19,24 million denars, at the same time we have $30,18 \%$ probability to have same or lower result of net income in 2020 .

Second row shows that in the case of values simulated with $10 \%$ decrese of net income we have probability of $26,21 \%$ which is the probability for the outcome for the value of net income will be higher than referent value of net income in 2020. Calculations on tis filtered sample present average net income value of 17,62 million denars. This result indicates that we have $26,21 \%$ probability of achieving average result of 17,62 million denars, at the same time we have $75,79 \%$ probability to have same or lower result of net income in 2020 .

In both cases we have indications that in case of lower positive or negative trend on the result produced from the increased or decreased value of net income we can see that we can expect $69,82 \%$, and $26,21 \%$ of same or higher value than in year 2020 . Interesting fact is that lower probability of $26,21 \%$ is in favor for decreased probability for good result in case of undesired variations.

Below are the figures representing the Power $\mathrm{BI}$ reports used as analytical tool and the test results for the Kuehne \& Nagel case when we use the data values which we produced from the same level as referent value of net income of year 2020 with higher than 16.08 million denars (16.083.212 denars).

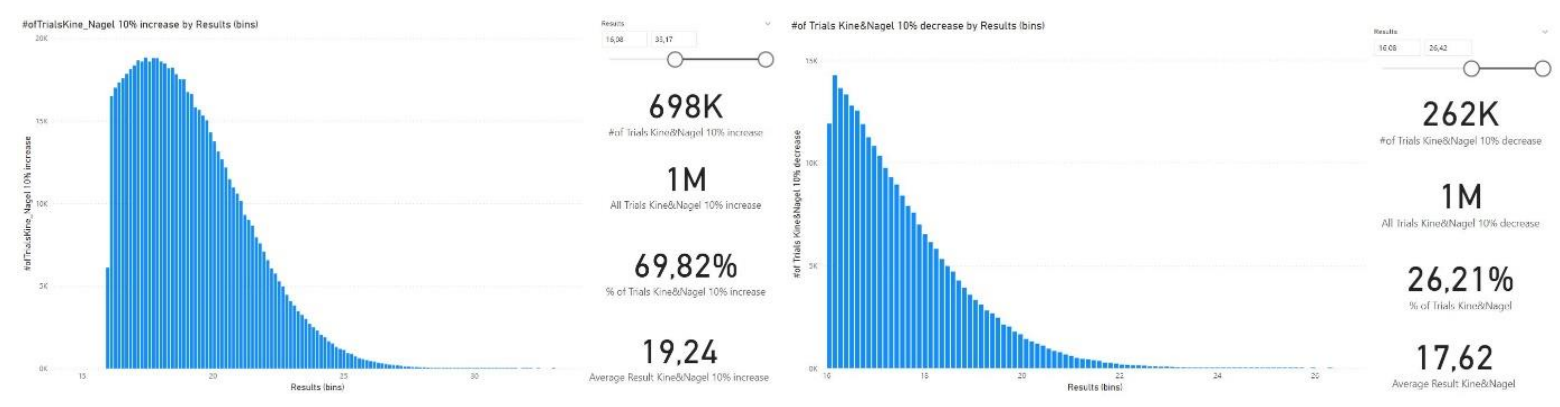

Figure 2 Power BI report used as analytical tool and the test results for the Kuehne \& Nagel

Source: Authors' calculations based on data from the Central Registry of the Republic of the North Macedonia www.crm.com.mk

\subsection{Quehenberger Logistics}

Quehenberger is a comprehensive transport and logistics provider, in the area of logistics at 94 locations in 18 countries. [8] The Salzburg-based company Quehenberger Logistics typically uses a wide range of transport modes - trains, trucks, planes and ships and thereby strives to optimally integrate the existing software solutions of the customer, to reduce the costs and strengthen effectiveness. Existing technologies are already playing important roles for ongoing services like as just in time (JIT) and just in sequence (JIS).[9]

Below are the test results for the Quehenberger Logistics case when we use the data values which we produced from the same level as referent value of net income of year 2020 with higher than 2.763.400 denars. 
Table 2 Results on data generated from generated data from referent value of net income for Quehenberger Logistics at level, 10\% increased and $10 \%$ decreased simulated values with input value of $<2.7634$ million denars

\begin{tabular}{|c|c|c|c|}
\hline & $\begin{array}{l}\text { \# Of } \\
\text { Trials }\end{array}$ & Probability & $\begin{array}{l}\text { Average result of net } \\
\text { income }\end{array}$ \\
\hline $\begin{array}{l}\text { Quehenberger Logistics } \\
10 \% \text { increase }\end{array}$ & $522 \mathrm{~K}$ & $52,20 \%$ & $7,01 \mathrm{M}$ \\
\hline $\begin{array}{l}\text { Quehenberger Logistics } \\
10 \% \text { decrease }\end{array}$ & $474 K$ & $47,38 \%$ & $6,06 \mathrm{M}$ \\
\hline
\end{tabular}

Source: Authors' calculations based on data from the Central Registry of the Republic of the North Macedonia www.crm.com.mk

Table 3 in the first case shows that in the case of values simulated with $10 \%$ increase of net income we have probability of $52,20 \%$, which is the probability for the outcome for the value of net income will be higher than referent value of net income in 2020. Calculations on tis filtered sample present average net income value of 7,01 million denars. This result indicates that we have $52,20 \%$ probability of achieving average result of 7,01 million denars, at the same time we have $47,8 \%$ probability to have same or lower result of net income in 2020 .

Second row shows that in the case of values simulated with $10 \%$ decrease of net income we have probability of $47,38 \%$ which is the probability for the outcome for the value of net income will be higher than referent value of net income in 2020. Calculations on tis filtered sample present average net income value of 6,06 million denars. This result indicates that we have $47,38 \%$ probability of achieving average result of 6,06 million denars, at the same time we have $52,62 \%$ probability to have same or lower result of net income in 2020 .

In both cases we have indications that in case of lower positive or negative trend on the result produced from the increased or decreased value of net income we can see that we can expect $52,20 \%$, and $47,38 \%$ of same or higher value than in year 2020 .

Analyzing the results which are little in favor of results of the same or lower than the values in 2020. This simulation having in mind preliminary assumptions from the research goals and high starting level of net income in 2020 in all scenarios indicate that we can expect strong positive results, and at least repeating the strong results of the net income from 2020. Below are the figures representing the Power BI reports used as analytical tool and the test results for the Kuehne \& Nagel case when we use the data values which we produced from the same level as referent value of net income of year 2020 with higher than 2.76 million denars (2.763.400 denars).
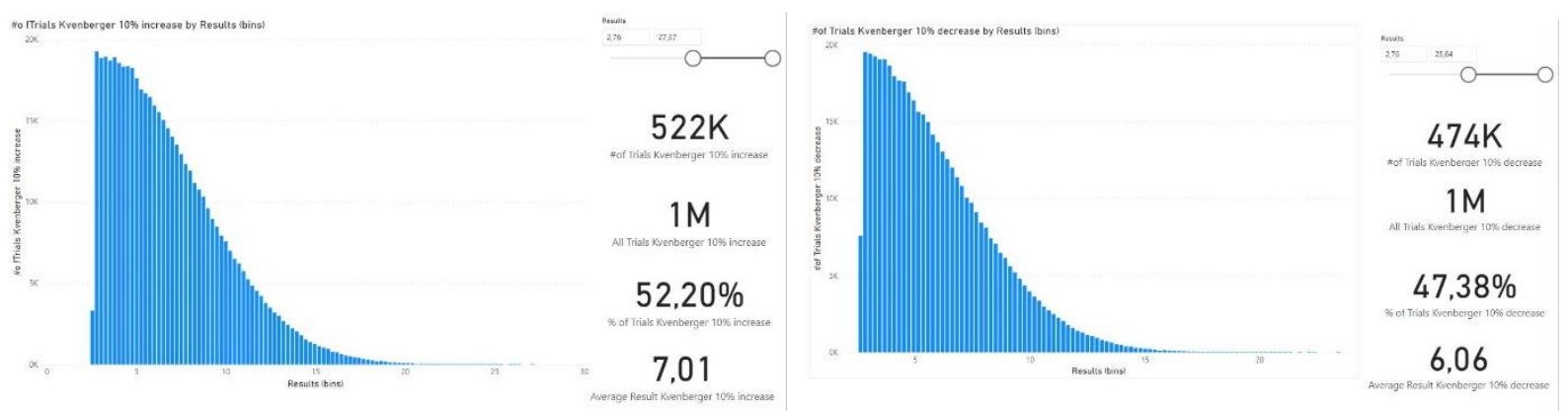

Figure 3 Power BI report used as analytical tool and the test results for the Quehenberger Logistics

Source: Authors' calculations based on data from the Central Registry of the Republic of the North Macedonia www.crm.com.mk 


\section{Conclusion}

Data analysis and different scenario investigation as well as reducing logistics costs are a significant measure of the profitability of any company, especially in the transport and logistics sector. Costs are often ignored because they are difficult to pinpoint their origin, specific carrierrelated losses, resources, processes, activities, and products. Without this, it is impossible to streamline, manage costs and achieve savings. Existing accounting systems and spreadsheets do not allow for a more precise differentiation of costs, so analysts have trouble determining exactly where individual costs appear and belong. A special problem is the distribution and projection and possible scenarios for improving the balance sheets of companies. To successfully solve these problems, it is necessary to apply a special methodology and procedure for measuring and monitoring costs, ie preparing and distributing reports on the structure and costs.

The main research hypothesis of this paper is determination of the probability for the net income level for the simulated data from 1 million trials. At the same time, we tend to introduce the Power BI and its visualization and analysis capabilities as recommended tool and suitable interactive environment for this and similar researches and thesis testing.

The subject of this paper is to analyze the potential of logistic companies and their performance capacity though the Monte Carlo simulation of the net income values. We present the case of Macedonian logistic companies with the challenge of goal testing. on 1 million data sample in two scenarios of $10 \%$ increased and decreased net income value. This case was tested on data from year 2020 for Fershped, Kuehne \& Nagel and Quehenberger Logistics as a part of Macedonian logistic industry.

Finding in all three cases in all three cases suggest achieving positive and relatively high average values of net income in all scenarios. However, if we know that the values in 2020 are continuing a good result from 2019, we can conclude that the results expected for 2021 will results in strong and positive values.

\section{References}

1. Tseng Y., Wen Long Y., Taylor A.P.M.: The role of transportation in logistics chain. Proceedings of the Eastern Asia Society for Transportation Studies, Vol. 5, 2005. pp. 1657 - 1672.

2. Christopher, M.: Logistics and supply chain management: creating value-adding networks / Martin Christopher. - 4th ed., 2011.стр. 2-3.

3. Kilibarda M., (2017): Tematski bilten: Transport I logistika: kljuc efikasnog poslovanja. Ekapija, 2017 str.16-17 http://www.ekof.bg.ac.rs/wp-content/uploads/2014/05/TEMATSKI-BILTEN-TRANSPORT-ILOGISTIKA-2017.pdf

4. Harrison, R.L., 2010, January. Introduction to Monte Carlo simulation. In AIP conference proceedings (Vol. 1204, No. 1, pp. 17-21). American Institute of Physics.

5. Rad, R., 2018. Power BI Components. In Pro Power BI Architecture (pp. 3-15). Apress, Berkeley, CA.

6. Fersped - company for international and local freight forwarding with public and bonded warehouses. http://www.fersped.com.mk/brief_introduction.aspx [accessed 28.01.2022]

7 Kuehne-Nagel global logistics company. https://home.kuehne-nagel.com/company/about [28.01.2022]

8. Quehenberger Logistics. https://www.quehenberger.com/en/Quehenberger/Locations [accessed 28.01.2022]

9. Temjanovski R. (2014): Challenges of information technology and supply chain management in logistic sector: with an overview of Quehenberger logistics in Macedonia. Beograd: Singidunum University International Conference, April $25^{\text {th }}-26^{\text {th }}$, The Impact of the Internet on Business Activities in Serbia and Worldwide.p.13. 